\title{
OCENA KULTUROLOŠKE SVESTI STANOVNIŠTVA PODRINJA
}

\section{Tamara Božović, Tatjana Pivac}

Univerzitet u Novom Sadu, Prirodno-matematički fakultet, Departman za geografiju, turizam i hotelijerstvo,

Novi Sad, Srbija
Correspondence:

Tamara Božović

e-mail:

tamaraabozovic@gmail.com

\section{Rezime:}

Podrinje predstavlja oblast koja se pruža duž cele obale reke Drine. Sa svojim prirodnim i stvorenim vrednostima Podrinje se nameće kao posebna i zaokružena turistička celina. Osnovna grupa turističkih vrednosti vezana je za hidrografske osobenosti reka i jezera, zatim je tu atraktivnost okolnog pejzaža, koja se zasniva na reljefnoj raznolikosti. Čvrsta podloga je i u kulturno-istorijskom nasleđu i kulturi. Osnovni ciljevi ovog rada su da pruži validne i detaljne podatke koji mogu ukazati na značaj koja kulturna dobra imaju za lokalno stanovništvo i koliko su sa njima upoznati. Rezultati ukazuju na veliku upoznatost lokalnog stanovništva sa kulturnim resursima Podrinja, ali i nedovoljnoj posećenosti pojedinih kulturnih resursa, što ukazuje da se mora raditi na promociji kulture među lokalnim stanovništvom, kao nosiocem kulture i razvoja destinacije.

Ključne reči:

kulturni turizam, lokalno stanovništvo, kulturološka svest, Podrinje

UVOD

Podrinje koje predstavlja oblast oko Drine po mnogo čemu je osobena i zanimljiva. Smenjuju se u njoj golo stenje, guste šume, pitomi voćnjaci, šljivici, livade, orahove šume i čitava polja kukuruza i duvana (Ristanović, 2000). Tragovi davne naseljenosti, pripadnost državi Nemanjića, prostor brojnih rudarskih središta, trgovačkih, zanatskih, zemljoradničkih i stočarskih naselja, najdužu i vodom najbogatiju pritoku Save čine zonom spajanja i prožimanja, ali i odvajanja i izolovanja (Blagojević et al., 2005).

Podrinjska regija se može posmatrati kao izrazito tranzitni prostor obzirom da se nalazi na granici dve države. Postojanje brojnih prirodnih osobenosti i antropogenih vrednosti ove prirodne regije ukazuje na polivalentnost. Polivalentnost se pre svega ogleda i u različitosti prirodnih lepota u okruženju i različitih oblika turizma koji su ovde zastupljeni. Kontaktnost je takođe važan element funkcionalnog položaja jedne destinacije i kada se govori o Podrinju može se reći da je ovde kontaktnost izražena. Nalazi se na granici dve države koje su na sličnoj lestvici ekonomskog razvoja, ne tako loš politički odnos takođe doprinosi razvoju turizma koji se ovde ogleda kroz kontaktnost (Marinoski et al., 2015). 
Imajući u vidu ogroman potencijal materijalne i duhovne kulture Podrinja, ovo područje ima sve potrebno da može na pravi način da oživi i predstavi tradiciju Srbije, poboljša ekonomske efekte ovog kraja i uključi lokalno stanovništvo u sve aktivnosti.

Svi oblici kulturnog turizma koji su zastupljeni na teritoriji Podrinja, međusobno se prepliću i čine jednu celinu. Ni jedan oblik turizma ne može se pojedinačno posmatrati i pratiti. Kao i u teoriji, i u praksi je potrebno napraviti jedinstvenu turističku ponudu koja bi obuhvatala različite ture kako bi privukle sve veći broj turista i obuhvatile, možda i nepravedno zapostavljene, resurse koji se mogu ponovo aktivirati u turističkoj ponudi.

Susreti turista sa lokalnim stanovništvom značajni su za gosta, jer mu pružaju željena saznanja o kraju i ljudima. Za domaćine, ti susreti predstavljaju mogućnost da nešto više saznaju o svetu i događajima (Stojanović, 2007).

\section{PREGLED LITERATURE}

Turizam može doneti niz prednosti, uključujući poboljšanje ekonomskih mogućnosti stvaranjem novih radnih mesta za stanovnike, povećanjem prihoda i stimulacijom ili stvaranjem lokalnih i regionalnih tržišta. Takođe, turizam može pomoći u zaštiti prirodnog i kulturnog nasleđa, očuvanjem vrednosti kroz obrazovanje i tumačenje, i pomoći u podršci istraživanju i razvoju dobrih praksi u oblasti zaštite životne sredine. Turizam može poboljšati kvalitet života kroz poboljšanu infrastrukturu, interkulturalno razumevanje i procenu vrednosti po lokalnom nivou ljudi, njihove kulture, njihove baština i tradicije (Tigu, 2012). Održivost turizma znači stvaranje radnih mesta za lokalnu zajednicu i obezbeđivanje lokalnog učešća u procesima planiranja i donošenja odluka (Minciu et al., 2010).

U turističkim kretanjima, krajem 20. i početkom 21. veka, ekspanziju doživljava kulturni turizam. Kulturni turizam kao oblik posebnog interesa i iskustvenog turizma zasnovan je na potrazi ili učešćem u novim i dubokim kulturnim iskustvima estetske, intelektualne, emocionalne ili psihološke prirode (Chen, Rahman, 2018). Šira definicija kulturnog turizma bi bila: "posete osoba izvan lokalne zajednice motivisane u potpunosti ili delimično interesovanjem za istorijski, umetnički, naučni ili životni stil/ponudu na nivou zajednice, regije ili institucije" (Silberberg, 1995). Kulturne destinacije mogu uključivati različite lokacije kao što su muzeji, festivali, arhitektura, baština i turističke atrakcije vezane za hranu, jezik i religiju (Stylianou-Lambert, 2011). Richards (1996) je predložio dve različite definicije kulturnog turizma. Njegova konceptualna definicija se odnosi na "kretanje ljudi ka kulturnim atrakcijama koje se nalaze van redovnog mesta prebivališta, s namerom da prikupe nove informacije i iskustva kako bi zadovoljile njihove kulturne potrebe" (Richards, 1996) dok tehnička definicija kaže "Sva kretanja ljudi prema određenoj kulturnoj znamenitosti, kao što su lokacije kulturnog nasleđa, umetničke i kulturne manifestacije, umetnost i drama, a koje se nalaze izvan njihovog mesta življenja" (Richards, 1996).

Kulturni turizam je naročito atraktivan zbog spektra prednosti koje može pružiti lokalnim zajednicama da ih razvija uz značajnu brzinu i neprekidno na više raznovrsnih načina. Donovan Rypkema u svojim istraživanjima naglašava vezu između očuvanja nasleđa i lokalne ekonomije, dajući primere kako dobra praksa kulturnog nasleđa utiče na lokalnu zajednicu (Rypkema, 2008). Lokalne zajednice se sve više uvlače u turizam ne samo sa strane potražnje, već i sa strane ponude, pošto zajednice postaju svesne potencijala proizvoda koje mogu ponuditi turistima i ekonomskih dobitaka koji se mogu ostvariti (Telfer \& Sharpley, 2008).

Bez obzira na to kako se turizam uvodi i razvija u zajednici, stanovnici su važni igrači koji mogu uticati na uspeh ili neuspeh lokalne turističke industrije. Stanovnici mogu doprineti dobrobiti zajednice kroz njihovo učešće u planiranju, razvoju i funkcionisanju turističkih atrakcija, i proširenjem svog gostoprimstva turistima u zamenu za beneficije koje se dobijaju od turizma (Ap, 1992).

\section{METODOLOGIJA}

Za potrebe ovog istraživanja korišćene su tehnike intervjua, upitnika i posmatranja, a sam cilj istraživanja jeste ocena kulturološke svesti i nivoa stanovništva okruga Podrinja. Zadaci istraživanja odnose se na nivo 
zainteresovanosti lokalnog stanovništva za kulturu Podrinja u zavisnosti od pola, uzrasta, platežne sposobnosti i obrazovanja istih. Takođe zadaci se odnose i na informisanost lokalnog stanovništva.

Za potrebe istraživanja kreirana je anketa sa 15 pitanja zatvorenog tipa, koji su ispitanici popunjavali u odštampanoj tekstualnoj verziji. Nivo uzorka je 100 slučajno izabranih ispitanika, koji su odabrani po geografskom kriterijumu prebivališta u okrugu Podrinju. Tokom anketiranja akcenat je stavljen na opštinu Loznica, Mali Zvornik, Ljubovija i Bajina Bašta. Istraživanje je sprovedeno u više navrata tokom juna i jula 2018. godine.

\section{Izgled upitnika}

Upitnik, koji je bio namenjen ispitivanju mišljenja meštana Podrinja o kulturnom turizmu, sastoji se od nekoliko segmenata pitanja. Prvi segment odnosi se na socio-demografske karakteristike ispitanika, što je samo uvod u daljoj analizi vrednovanja kulturnih resursa.

Drugi segment pitanja, odnosio se na procenu značaja navedenih kulturnih atrakcija Podrinja kroz kvantitativno turističko vrednovanje, prikazujući ih od najznačajnijih do manje značajnih.

Sledeći segment pitanja odnosi se na lokalnu posećenost kulturnih resursa, odnosno koliko često ispitanici posećuju već spomenuta kulturna dobra.

$\mathrm{U}$ četvrtom segmentu anketnog istraživanja pitanja se odnose na valorizaciju navedenih resursa. Elementi na osnovu kojih su davane ocene su: lokacija i dostupnost, umetnička vrednost, monumentalnost i jedinstvenost, očuvanost i zaštita, turistička posećenost, prepoznatljivost, postojanje informativnih tabli, signalizacija $\mathrm{i}$ isticanje u turističkoj promociji.

Peti deo anketnog upitnika istražuje mišljenje ispitanika o turističkoj propagandi i plasiranju informacija o kulturnim atraktivnostima, koje mogu imati veoma veliki značaj za buduća turistička kretanja.

\section{Uzorak}

Kada je u pitanju polna struktura ispitanih stanovnika Podrinja, za nijansu je veći broj osoba ženskog pola (54\%) u odnosu na anketirane osobe muškog pola (46\%). Najveći broj ispitanika pripada starosnoj grupi između 31 i 40 godina (30\%), što ukazuje da je ona najviše zainteresovana za kulturni turizam.

Najmanje ispitanika pripada grupi koja ima od 41-50 godina (12\%), dok ispitanika koji imaju više od 60 godina nema među anketiranima. Na drugom mestu je starosna struktura koja ima od 21- 30 (26\%), a na trećem mestu nalazi se grupa starosti od 51-60 godina. Kada se posmatra ekonomska struktura stanovništva ispitanih građana Podrinja, uočava se da dominira segment zaposlenih (62\%). Na drugom mestu jesu studenti koje imaju udeo od 16\%, a zatim slede nezaposleni i učenici sa učešćem od 10\%. Na zadnjem mestu nalaze se penzioneri koji čine $2 \%$ ispitanika. Najveći broj ispitanika u posmatranom uzorku ima srednjoškolsko obrazovanje (50\%). Ispitanici sa završenim fakultetom su na drugom mestu sa $36 \%$ učešća, a na trećem mestu su ispitanici sa završenim master studijama (12\%). Najmanji broj čini segment ispitanika sa osnovnom školom (2\%), dok ispitanika sa završenim doktorskim studijama nema. Visina primanja stanovnika Podrinja na mesečnom nivou direktno utiče na odluku o putovanjima. Kako je suština ispitivanja analiza mišljenja stanovništva o kulturnom turizmu, visina mesečnih primanja je varijabla koja utiče na kretanja na užem kontraktivnom području. Najveću grupu ispitanika čine oni koji na mesečnom nivou imaju primanja od 301-500€, što se objašnjava opštim ekonomskim tokovima na državnom nivou. Na drugom mestu sa malom razlikom u broju ispitanika, jesu ispitanici koji imaju primanja od 101-300€ (26\%). Na trećem mestu su ispitanici koji imaju primanja do $100 €$, i oni koji su bez primanja. Najmanju grupu ispitanika, sa svega $4 \%$ čine oni koji imaju primanja između 500 i $700 €$. Geografski kriterijum deli ispitanike na grupe prema opštinama prebivališta u Podrinju. Najveći odaziv ispitanika bio je iz opštine Loznice sa učešćem od 36\% koji su dali najveći doprinos istraživanju. Na drugom mestu su ispitanici iz Ljubovije (28\%), dok su ispitanici iz Malog Zvornika i Bajine Bašte učestvovali podjednako sa $18 \%$. 
Na osnovu prikazane socio-demografske strukture ispitanih stanovnika Podrinja može se zaključiti da su za kulturu, i uključivanje u kulturne tokove Podrinja, najviše zainteresovani ispitanici između 30 i 40 godina, koji su zaposleni i fakultetski su obrazovani. Takođe, ispitan je i veliki broj mladih ljudi, što predstavlja pozitivnu zainteresovanost mlađih generacija za promene i poboljšanje ovog vida turizma u Podrinju.

\section{REZULTATI I DISKUSIJA}

Jedan od najvažnijih kulturnih resursa na teritoriji Podrinja za stanovnike predstavljaju spomenici kulture sa prosečnom ocenom 4,46, kao i manastiri i crkve sa prosečnom ocenom 4,36. Manastiri i spomenici kulture na području Podrinja imaju veoma dugu tradiciju, i ne samo umetničku već i duhovnu vrednost kod stanovništva kroz vekove i burnu istoriju ovog podneblja. Na trećem mestu po važnosti su gastronomija i piće, kao zaštitni znak Podrinja koji može biti velika prednost u prezentaciji Podrinja, čak $44 \%$ ispitanika smatra da su gastronomija i piće izuzetno važni.

Nakon toga po važnosti su svrstane manifestacije, prostorno kulturno-istorijske celine, arheološka nalazišta i znamenita mesta i spomen obeležja sa prosečnim ocenama iznad 4, dok su nešto nižu ocenu imaju narodni običaji i vašari $(3,86)$, folklor i nošnja $(3,92)$, dela sa spomeničkim i umetničkim vrednostima $(3,9)$. Muzeji i galerije za stanovnike Podrinja predstavljaju kulturne resurse sa najmanjom vrednošću, svega 3,52 prosečna ocena. Ovo govori da se mora više uložiti u prezentaciju galerija, muzeja i ustanova kulture kako bi se što više približili stanovništvu i samim tim da bi se stanovništvo bolje upoznalo sa radom tih ustanova koje imaju veliku kulturnu vrednost svakog kraja.

Kada se posmatra posećenost kulturnih resursa od strane lokalnog stanovništva, može se zaključiti da su arheološka nalazišta kulturni resurs koji imaju ujednačenu posećenost, 5\% stanovništva redovno posećuje nalazišta, dok $43 \%$ stanovništva ponekad posećuje, a $35 \%$ ispitanika to čini retko. Spomenici kulture nikada ne posećuje samo $2 \%$ stanovništva, dok $33 \%$ stanovnika to čini često što govori o solidnoj posećenosti ovog resursa.

Kada se posmatraju manastiri i crkve, kao i prostorne kulturno-istorijske celine, ne postoje stanovnici Podrinja koji ove kulturne resurse nikada ne posećuju. Manastiri i crkve imaju veliku posećenost, sa čak 50\% stanovništva koje često posećuje ove resurse. Prostorne celine najviše su posećeni resursi u celom Podrinju sa čak 41\% stanovništva koje uvek posećuje ove kulturne resurse, i 35\% stanovništva koje to čini često.

Znamenita mesta imaju prilično ujednačenu podelu kada su posete lokalnog stanovništva u pitanju. Ne postoje ispitanici koji nikada ne posećuju ove kulturne resurse. Isti broj ispitanika sa jedne strane uvek, a sa druge strane retko posećuje znamenita mesta, i taj broj čini 8 \%ispitanika. Takođe, isti procenat ispitanika (42\%) često i ponekad posećuje znamenita mesta, tako da se može zaključiti da je posećenost dobra. Muzeji i galerije uvek posećuje 33\% stanovništva, a $4 \%$ i $6 \%$ nikada i retko.

Manifestacije su nedovoljno posećene od strane lokalnog stanovništva, samo samo 14\% ispitanika koji ih često posećuju i $16 \%$ onih koji to čine često. Čak $11 \%$ ispitanika navodi da nikada ne posećuje kulturne manifestacije u svom kraju. Manifestacije su veoma važne za očuvanje kulture i tradicije i njeno prezentovanje kako lokalnom stanovništvu tako i stranim i domaćim turistima koji posete određeni kraj.

Zaključuje se da je potrebno više uključiti lokalno stanovništvo da posećuje, i da učestvuje u samim manifestacijama, jer je stanovništvo deo kulture koja se predstavlja kroz te iste manifestacije.

$\mathrm{U}$ četvrtom segmentu anketnog istraživanja pitanja se odnose na valorizaciju navedenih resursa. Elementi na osnovu kojih su davane ocene su: lokacija i dostupnost, umetnička vrednost, monumentalnost i jedinstvenost, očuvanost i zaštita, turistička posećenost, prepoznatliivost, postojanje informativnih tabli, signalizacija $\mathrm{i}$ isticanje u turističkoj promociji. Kulturni resursi su ocenjivani na skali od 1 do 5 . U tabeli 1 su prikazani rezultati koji su predstavljeni kao prosek dobijenih ocena od strane anketiranih lica i nude jasnu sliku vezanu za kulturne resurse. 
Tabela 1. Lokalno vrednovanje kulturnih vrednosti

\begin{tabular}{|c|c|c|c|c|c|c|c|c|}
\hline KULTURNI RESURSI & 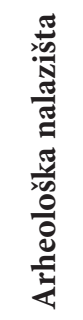 & 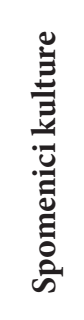 & 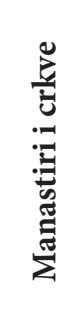 & 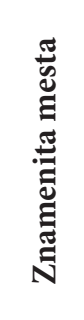 & 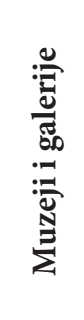 & 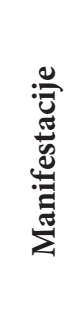 & 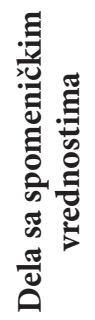 & 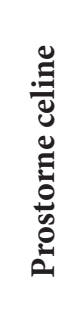 \\
\hline Lokacija i dostupnost & 2,47 & 4,06 & 4,24 & 4,04 & 4,04 & 4,14 & 3,92 & 3,72 \\
\hline Umetnička vrednost & 3,38 & 4 & 4,4 & 4,22 & 4,08 & 4 & 3,98 & 3,76 \\
\hline Monumentalnost i jedinstvenost & 3,64 & 3,8 & 4,36 & 4,26 & 3,96 & 3,72 & 3,5 & 3,76 \\
\hline Očuvanost i zaštita & 2,68 & 3,8 & 4,08 & 3,16 & 3,8 & 3,6 & 3,44 & 3,48 \\
\hline Turistička posećenost & 2,86 & 3,66 & 3,86 & 3,48 & 3,42 & 3,42 & 3,5 & 3,6 \\
\hline Prepoznatljivost & 3,12 & 3,86 & 3,9 & 3,76 & 3,5 & 3,56 & 3,8 & 3,78 \\
\hline Postojanje informativnih table, signalizacije... & 2,53 & 3,43 & 3,78 & 3,67 & 3,23 & 3,36 & 3,12 & 3,47 \\
\hline Isticanje u turističkoj promociji & 2,37 & 3,29 & 3,71 & 3,69 & 3,32 & 3,32 & 3,27 & 3,12 \\
\hline
\end{tabular}

Izvor: Izrada autora

Na osnovu tabele 1 može se uočiti da kada je u pitanju lokacija i dostupnost arheološka nalazišta imaju najmanju prosečnu ocenu $(2,47)$, dok prema mišljenju ispitanika manastiri i crkve imaju najveću srednju ocenu blizu maksimalnoj vrednosti $(4,24)$. Takve prosečne ocene odgovaraju realnom trenutnom stanju. Često se arheološki lokaliteti nalaze na teško pristupačnim mestima do kojih turisti mogu doći jedino u slučaju da veoma dobro poznaju teren.

Umetnička vrednost kulturnih dobara koji su predmet ocenjivanja od strane ispitanika kreće se u rasponu od 3,76 do 4,4 a slične srednje vrednosti ima i monumentalnost i jedinstvenost kulturnih dobara. Ni jedan od kulturnih resursa prema ispitanicima nema maksimalnu umetničku vrednost. Najveću ocenu imaju manastiri i crkve sa 4,4. a zatim znamenita mesta sa prosečnom ocenom 4,22. Spomenici kulture imaju visoku umetničku vrednost sa ocenom 4 .

Kada se posmatra monumentalnost i jedinstvenost kulturnih resursa, prva dva mesta sa najvišim prosečnim ocenama pripala su manastirima i crkvama i znamenitim mestima, dok dela sa spomeničkim vrednostima imaju nešto nižu srednju ocenu od 3,5.

Kategorija očuvanost i zaštita ima znatno niže prosečne ocene. Donju granicu ocena dodeljenih od strane anketiranih učesnika u okviru ove kategorije imaju prostorne celine sa prosečnom ocenom 3,4. Turistička posećenost najbolje pokazuje u kojoj meri se neko dobro može nazvati turističkom atraktivnošću.

Najlošiju ocenu po mišljenju ispitanika zaslužuju arheološka nalazišta a odmah zatim muzeji i galerije i manifestacije, a visoku posećenost uživaju prostorno kulturno istorijske celine, sa prosečnom ocenom 3,6. Obim posete ostalih kulturnih dobara kreće se u rasponu od 2-3. U kategoriji prepoznatljivosti, anketirane osobe najvišu ocenu od 3,9 dale su takođe manastirima, a zatim slede dela sa spomeničkim vrednostima i spomenici kulture. Najnižu ocenu dobile su arheološka nalazišta koja čekaju bolja vremena kada će restauracijom i konzeracijom dobiti pravi izgled i veću vrednost. Po mišljenju ispitanika turističkoj promociji treba posvetiti mnogo više pažnje u svim segmentima kulturnih dobara i ni jedan od pomenutih vrednosti nema veliku prepoznatljivost. Kao što se iz priloženog može videti, najmanje ocenjen indikator sa 2,37 je isticanje u promociji, a najveća je 4,26 odnosno monumentalnost i jedinstvenost kulturnih resursa. Iako su stručnjaci iz oblasti kulturnog turizma najmerodavniji da daju ocene vezane za umetničku vrednost, monumentalnost i jedinstvenost, činjenica da ju je lokalno stanovništvo prepoznalo.

Peti deo anketnog upitnika istražuje mišljenje ispitanika o turističkoj propagandi i plasiranju informacija o kulturnim atraktivnostima, koje mogu imati veoma veliki značaj za buduća turistička kretanja. 
Na osnovu istraživanja može se zaključiti da najveću informativnu ulogu ima preporuka prijatelja koji daju pozitivna mišljenja i iskustva o kulturnoj atrakciji koju su posetili. Informativne table predstavljaju značajan nedostatak na teritoriji okruga, ali bez obzira na to količina informacija koja se putem njih dobija je relativno dobra. Procenat onih koji se ne slaže sa tim je $24 \%$. Kroz razgovor sa stručnim licima, odnosno zaposlenima u muzejima, galerijama i drugim institucijama, predstavnicima turističkih organizacija mogu se dobiti značajne informacije i procenat ispitanika koji se slažu sa tom tvrdnjom je 33\%. Organizovanje naučnih skupova i seminara na kojima postoji interakcija stručnjaka i publike, može značajno izmeniti ovu statistiku. Može se primetiti, takođe, da je veliki broj informacija koje se koriste dobija preko internet promocije, koja je sa napretkom tehnologije, društvenih mreža i dr. u sve većoj ekspanziji i ima sve veću važnost.

Poslednji segment anketnog upitnika bio je namenjen za sugestije i komentare stanovništva za poboljšanje kulturnog turizma u Podrinju. Najveći broj ispitanika ukazao je na nezadovoljstvo sadašnjim marketinškim aktivnostima, jer većina lokalnog stanovništva nije čulo za pojedina kulturna dobra i manifestacije u svojoj okolini. Ispitanici smatraju da je potrebno više dati na značaju promociji i više je unaprediti. Zato bi trebalo da se lokalne vlasti u saradnji sa turističkim organizacijama povežu sa osnovnim i srednjim školama i organizuju ekskurzije kako bi se, na prvom mestu, đaci upoznali sa istorijom i kulturom svoje okoline. Na ovaj način putem ekskurzija, ne samo omladine, već i šire grupe segmenata, stvaraju se uslovi za razvoj navika posetilaca.

\section{ZAKLJUČAK}

Lokalno stanovništvo mora postepeno sticati i negovati kulturne navike kako bi se razvio podsticaj za povezivanje kulture i turizma. Edukacija za najmlađe stanovnike je ulaganje u budućnost kroz kreiranje interesovanja za kulturne vrednosti. Programi prilagođeni uzrastu omogućavaju lakša učenja i usvajanja informacija o istoriji i umetnosti. Vremenom, oni postaju najmerodavniji pokazatelji kulturnog nivoa stanovništva i važni činioci turističkih kretanja. Za razvoj kulturnog turizma jednog grada može biti iskorišćeno industrijsko nasleđe, koje je postalo veoma popularno krajem dvadesetih godina.

Sve ono kako se nekada radilo, kako se i od čega pravilo, čime se proizvodilo, može da bude posebna atrakcija za turiste. Neiskorišćene industrijske zgrade mogu biti pretvorene u galerije, studije za umetnike, radionice, školski prostor i mesto drugih aktivnosti za koje trenutno ne postoji adekvatan prostor.

Pored promovisanja kulturnih dobara neophodno je promovisati i manifestacija, kao i uvođenje još većeg broja istih. Ispitanici smatraju da je Podrinje veoma pogodno područje i da ima veliki potencijal i osnovu za osnivanje raznih manifestacija i da to više treba iskoristiti. Manifestacije su atrakcije koje imaju veliku popularnost i gde je neophodno raditi na osvežavanju programa kako bi se one i zadržale i privukle veliki broj turista. Neophodno je češće organizovati skupove na kojima bi se prezentovalo etnografsko nasleđe, odnosno folklor, narodna nošnja i gastronomija i na taj način približiti kulturu samog kraja.

Ispitanici su naglašavali neophodnost turističkog uređenja prostora. Najveći akcenat je stavljen na konkretnu zaštitu dobara od propadanja i kroz usvajanje novih strategija konzervacije, što se posebno odnosilo na manastire i arheološka nalazišta.

Najbolji primer sinergije više turističkih motiva u jedan prostor jeste kombinacija kulturno-istorijskih spomenika i prirodnih lepota u Podrinju. Razvoj turističke privrede, na direktan ili indirektan način može doprineti boljitku, uključivanjem lokalnog stanovništva. To se može učiniti na razne načine, preporukom prijatelja, uključivanjem volontera u turističke akcije i dr.

Na osnovu dosadašnje analize kulturnog turizma u Podrinju, zaključuje se da se radi o turistički nedovoljno razvijenom području. Turizam je prepoznat kao razvojna šansa ovog dela Podrinja, međutim njegov razvoj još uvek se nalazi u početnoj fazi i zahteva znatno unapređenje. Turizam na ovom prostoru ima dugu tradiciju, ali za dalji razvoj neophodno je ulagati pre svega u infrastrukturu, bolju opremljenost smeštajnih kapaciteta, uređenju i opremanju turističkih lokaliteta, razvoju novih atraktivnih proizvoda, itd. Turizam zahteva konstantna ulaganja, inovacije, prilagođavanje ljudskim potrebama i navikama savremenog doba, turizam zahteva vizionarstvo. 
Ap, J. (1992). Residents' perceptions on tourism impacts. Annals of Tourism Research, 19, 665-690. DOI:10. 1016/0160-7383(92)90060-3

Blagojević, M., Vlahović, P.,Gavrilović, D.,Dimitrijević, R., Živojinović, D., Mileusnić, S., Simonović, P., Stamenković, S.,\& Stanković, S.(2005). Drina. Beograd: Zavod za udžbenike.

Chen, H., \& Rahman, I. (2018). Cultural tourism: An analysis of engagement, cultural contact, memorable tourism experience and destination loyalty. Tourism Management Perspectives, 26, 153-163. DOI:10.1016/j. tmp.2017.10.006

Marinoski, N., Stamenković, P., \& Ilić, D. (2015). Turistička geografija. Leskovac: Visoka poslovna škola strukovnih studija.

Minciu, R., Popescu, D., Pădurean, M., Hornoiu, R., \& Bălțărețu, A. (2010). Comercializarea vacanțelor în ariile naturale protejate - formă a dezvoltării durabile în turism. Amfiteatru Economic. 27, 87-100. Retrieved from http://www.amfiteatrueconomic.ro/

Richards, G. (Ed.). (1996). Cultural tourism in Europe. Arnhem : ATLAS, Association for Tourism and Leisure Education

Ristanović, S. (2000). Reka Drina i Podrinje. Beograd: Vulkan.

Rypkema, D. D. (2008). Heritage Conservation and the Local Economy. Global Urban Development, 4(1), 1-8.

Silberberg, T. (1995). Cultural tourism and business opportunities for museums and heritage sites. Tourism Management, 16(5), 361-365. DOI: 10.1016/0261-5177(95)00039-Q

Stojanović, V. (2007). Prirodno okruženje i autentična kultura u seoskom turizmu. , Novi Sad : Prirodnomatematički fakultet, Departman za geografiju, turizam i hotelijerstvo.

Stylianou-Lambert, T. (2011). Gazing from home: Cultural tourism and art museums. Annals of Tourism Research, 38(2), 403-421. DOI:10.1016/j.annals.2010.09.001

Telfer, D. J., \& Sharpley, R. (2008). Tourism and Development in the Developing World. Abingdon (Oxon) and New York: Routledge.

Tigu, G. (2012). New Challenges for Tourism Destination Management in Romania, Strategies for Tourism Industry - Micro and Macro Perspectives. InTech, Retrieved from: http://www.intechopen.com/books/ strategies-for-tourism-industry-micro-andmacroperspectives/ new-challenges-for-tourism-destinationmanagement-in-Romania. DOI:10.5572/38798

\title{
ASSESSMENT OF THE CULTURAL AWARENESS OF THE POPULATION OF PODRINJE
}

\begin{abstract}
:
Podrinje represents an area that is spreading along the whole river bank of the Drina River. With its natural and created values, Podrinje is imposed as a special and rounded tourist unit. The basic group of tourist values is related to the hydrographic characteristics of rivers and lakes, then there is the attractiveness of the surrounding landscape, which is based on relief diversity. It is also a solid foundation in cultural and historical heritage and culture. The main aims of this paper are to provide valid and detailed data that can indicate the importance of cultural heritage to the local population and how familiar they are with them. The results point to the great familiarity of the local population with the cultural resources of Podrinje, as well as the insufficient attendance of certain cultural resources, which indicates that the culture must be promoted among the local population as the bearer of culture and the development of the destination.
\end{abstract}

Keywords:

cultural tourism, local population, cultural awareness, Podrinje 